\title{
Influence of Cr-Substitution on the Electrical Properties of $\mathrm{Fe}_{1-x} \mathrm{Cr}_{x} \mathrm{SnSbO}_{6}$
}

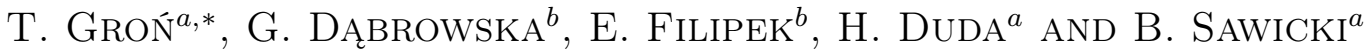 \\ ${ }^{a}$ University of Silesia, Institute of Physics, Uniwersytecka 4, 40-007 Katowice, Poland \\ ${ }^{b}$ West Pomeranian University of Technology in Szczecin, Department of Inorganic and Analytical Chemistry, \\ al. Piastów 42, 71-065 Szczecin, Poland
}

\begin{abstract}
$\mathrm{Fe}_{1-x} \mathrm{Cr}_{x} \mathrm{SnSbO}_{6}$ solid solution shows semiconducting behaviour with the activation energy decreasing from $E_{\mathrm{A}}=0.64 \mathrm{eV}$ for $x=0.0$ to $E_{\mathrm{A}}=0.32 \mathrm{eV}$ for $x=1.0$ in the intrinsic conductivity temperature region as well as the $n$-type conduction at room temperature. The $I-V$ characteristics and the conductance $G$ at 300 and $400 \mathrm{~K}$ showed symmetrical and nonlinear behavior in the voltage range $(-100,100 \mathrm{~V})$ suggesting the electron emission over the potential barrier especially for the boundary compounds $\mathrm{FeSnSbO}_{6}$ and $\mathrm{CrSnSbO}_{6}$. These effects are discussed in the context of the energy gap $E_{\mathrm{g}}>1.6 \mathrm{eV}$ many times greater than the thermal energy $k T$.
\end{abstract}

DOI: $10.12693 /$ APhysPolA.129.153

PACS/topics: 72.20.Pa, 72.80.Ga, 75.20.--g

\section{Introduction}

The oxides $\mathrm{SnO}_{2}, \mathrm{Fe}_{2} \mathrm{O}_{3}, \mathrm{Cr}_{2} \mathrm{O}_{3}$, and $\mathrm{Sb}_{2} \mathrm{O}_{4}$ and known compounds formed with the participation of these oxides, due to their chemical, magnetic, electrical and catalytic properties are particularly attractive for basic research and for a large number of prospective applications. The compounds, which are formed with the participation of said oxides include, among others, $\mathrm{FeSnSbO}_{6}$ and $\mathrm{CrSnSbO}_{6}$. These compounds are isostructural, they crystallize in the tetragonal system and they have the rutile-type structures $[1,2]$. A new continuous substitution solid solution of a $\mathrm{Fe}_{1-x} \mathrm{Cr}_{x} \mathrm{SnSbO}_{6}$ type is formed in the $\mathrm{FeSnSbO}_{6}-\mathrm{CrSnSbO}_{6}$ system. The phase has been obtained in air by the high-temperature solidstate reaction from appropriate mixtures of oxides and from the specially synthesized compounds: $\mathrm{CrSnSbO}_{6}$ and $\mathrm{FeSnSbO}_{6}$ [3]. In $\mathrm{Fe}_{1-x} \mathrm{Cr}_{x} \mathrm{SnSbO}_{6}$, the crystal lattice of the solid solution diminishes as $x$ decreases, which is manifested as decreasing volumes of unit cells.

Recently, the ultraviolet-visible and near-infrared (UV-Vis-NIR) diffuse reflectance spectra recorded at room temperature and in the wavelength range of $200-800 \mathrm{~nm}$ as well as transformed using the Kubelka-Munk function [4] showed that the energy gap, $E_{\mathrm{g}}$, in $\mathrm{Fe}_{1-x} \mathrm{Cr}_{x} \mathrm{SnSbO}_{6}$ increases nonmonotonically with increasing content $x$, i.e. $E_{\mathrm{g}}=1.67$, $1.88,1.89,1.96$ and $2.01 \mathrm{eV}$ for $x=0.0,0.25,0.5,0.75$, and 1.0, respectively [5]. These values of energy gap are characteristic for the semiconductors with low conductivity.

*corresponding author; e-mail: Tadeusz.Gron@us.edu.pl
This paper presents the electrical properties of $\mathrm{Fe}_{1-x} \mathrm{Cr}_{x} \mathrm{SnSbO}_{6}$ solid solutions as well as the considerations on the electron emission over the potential barrier.

\section{Experimental details}

The electrical conductivity $\sigma(T)$ and the $I-V$ characteristics of $\mathrm{Fe}_{1-x} \mathrm{Cr}_{x} \mathrm{SnSbO}_{6}$ have been measured in the intrinsic region with the aid of the DC method in the temperature range 300-400 K using a KEITHLEY 6517B Electrometer/High Resistance Meter. The thermoelectric power $(S)$ was measured at room temperature with the aid of a Seebeck Effect Measurement System (MMR Technologies, Inc., USA).

\section{Results and discussion}

The results of $\sigma(T)$ measurements of $\mathrm{Fe}_{1-x} \mathrm{Cr}_{x} \mathrm{SnSbO}_{6}$ (where $x=0.0,0.25,0.5,0.75,0.9,1.0$ ) showed a typical Arrhenius behaviour in the intrinsic region with the activation energy in the temperature range $350-400 \mathrm{~K}$. The activation energy $E_{\mathrm{A}}$, determined from the formula $\sigma=\sigma_{0} \exp \left(-E_{\mathrm{A}} / k T\right)$, decreases from $0.64 \mathrm{eV}$ for $x=0.0$ to $0.32 \mathrm{eV}$ for $x=1.0$. In general, the large conductivity and large carrier activation for the boundary compounds $\mathrm{FeSnSbO}_{6}$ and $\mathrm{CrSnSbO}_{6}$ are only observed (Fig. 1). The $I-V$ characteristics at 300 and $400 \mathrm{~K}$ (Figs. 2 and 3) show symmetrical behavior in the voltage range $(-100,100 \mathrm{~V})$ and the conductance $G$ increases nonlinearly with the increasing voltage (Figs. 4 and 5). The results of thermoelectric power $(S)$ measurements of $\mathrm{Fe}_{1-x} \mathrm{Cr}_{x} \mathrm{SnSbO}_{6}$ solid solutions at room temperature showed the $n$-type conductivity for all samples, i.e.: $S=-780,-302,-285$, and $-280 \mu \mathrm{V} / \mathrm{K}$ respectively for $x=0.0,0.5,0.9$, and 1.0 . 


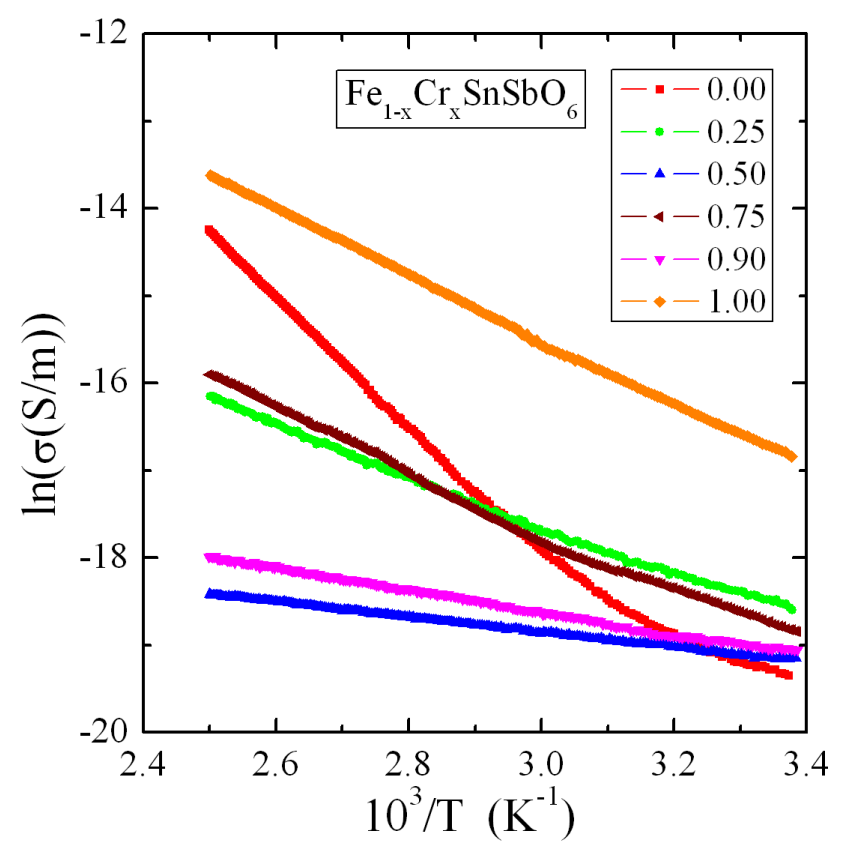

Fig. 1. Electrical conductivity $(\ln \sigma)$ vs. reciprocal temperature $\left(10^{3} / T\right)$ for $\mathrm{Fe}_{1-x} \mathrm{Cr}_{x} \mathrm{SnSbO}_{6}$.

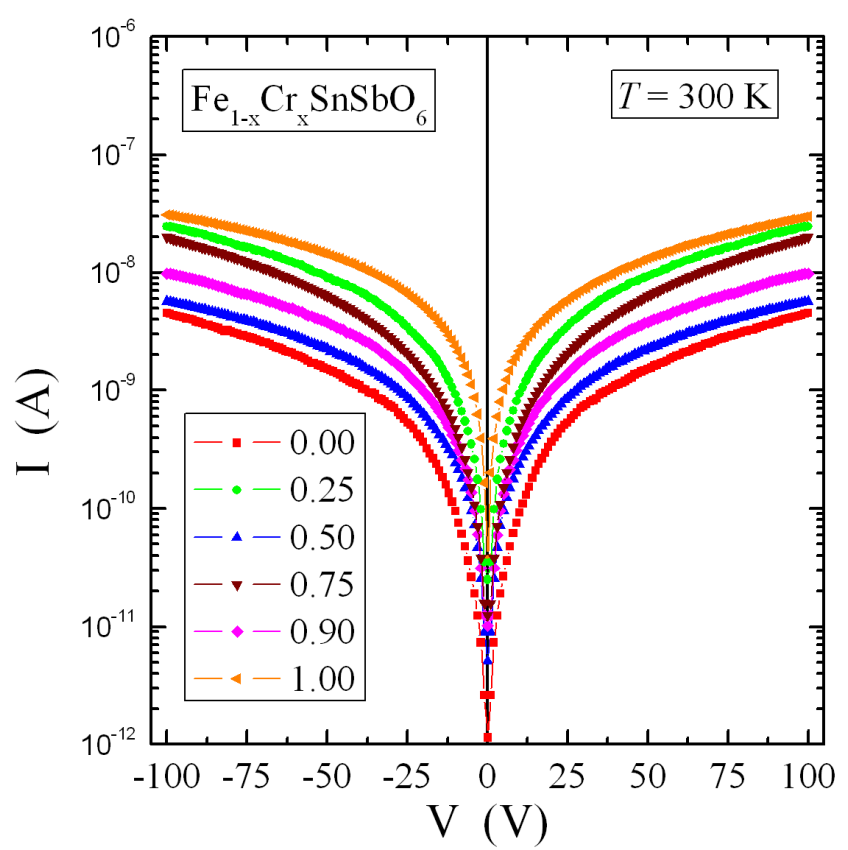

Fig. 2. The $I--V$ characteristics of $\mathrm{Fe}_{1-x} \mathrm{Cr}_{x} \mathrm{SnSbO}_{6}$ at $300 \mathrm{~K}$.

The question arises what mechanism is responsible for the electrical conductivity and the electron emission in the solid solutions under study. Our polycrystals are weak semiconductors with the energy gap of more than $1.6 \mathrm{eV}$ [5]. Therefore, it is unlikely that the thermal energy $k T$ is able to activate the electrons to the conduction band.

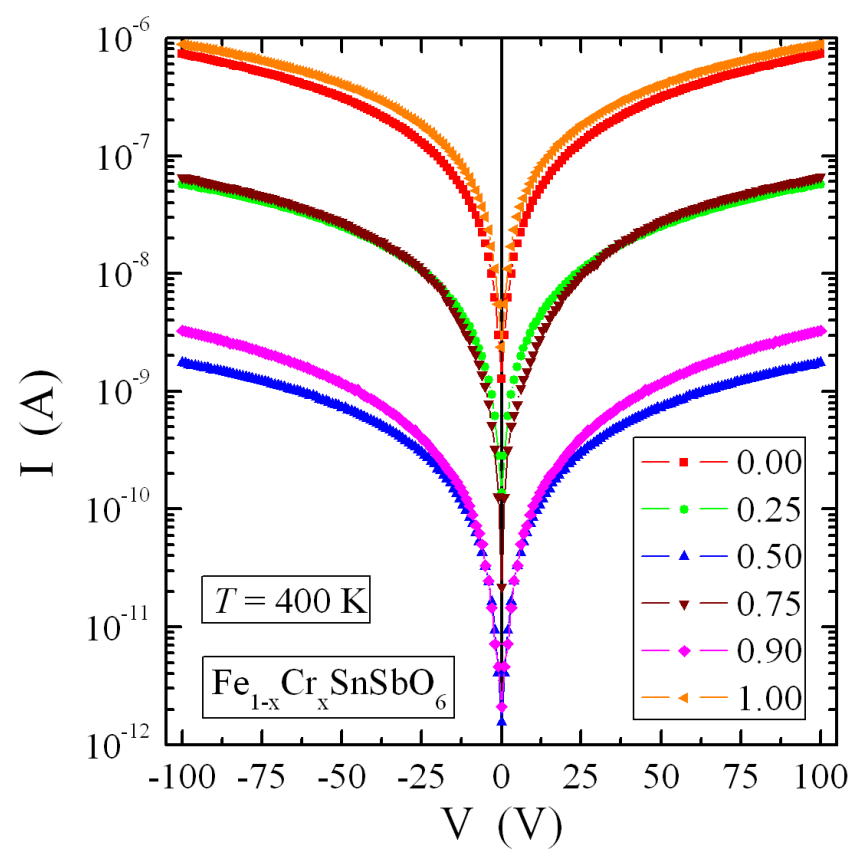

Fig. 3. The $I--V$ characteristics of $\mathrm{Fe}_{1-x} \mathrm{Cr}_{x} \mathrm{SnSbO}_{6}$ at $300 \mathrm{~K}$.

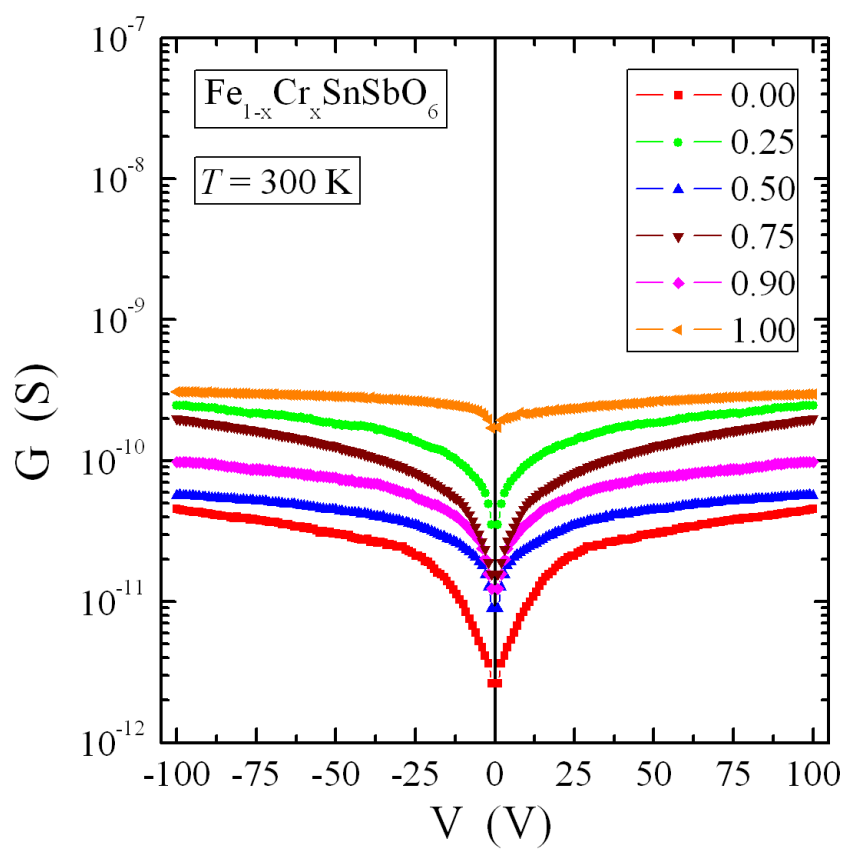

Fig. 4. Conductance $G$ vs. the applied voltage $V$ of $\mathrm{Fe}_{1-x} \mathrm{Cr}_{x} \mathrm{SnSbO}_{6}$ at $300 \mathrm{~K}$.

It is well known that in a case of low carrier concentration the thermionic emission processes may occur and the carrier transport can take place over the potential barrier. The not-increased carrier emission is characteristic for the ohmic behavior for which the voltage dependence of amperage $(I \propto V)$ is linear for $V \leq 0.2 \mathrm{~V}$ [6]. Carrier emission can be increased by the: 


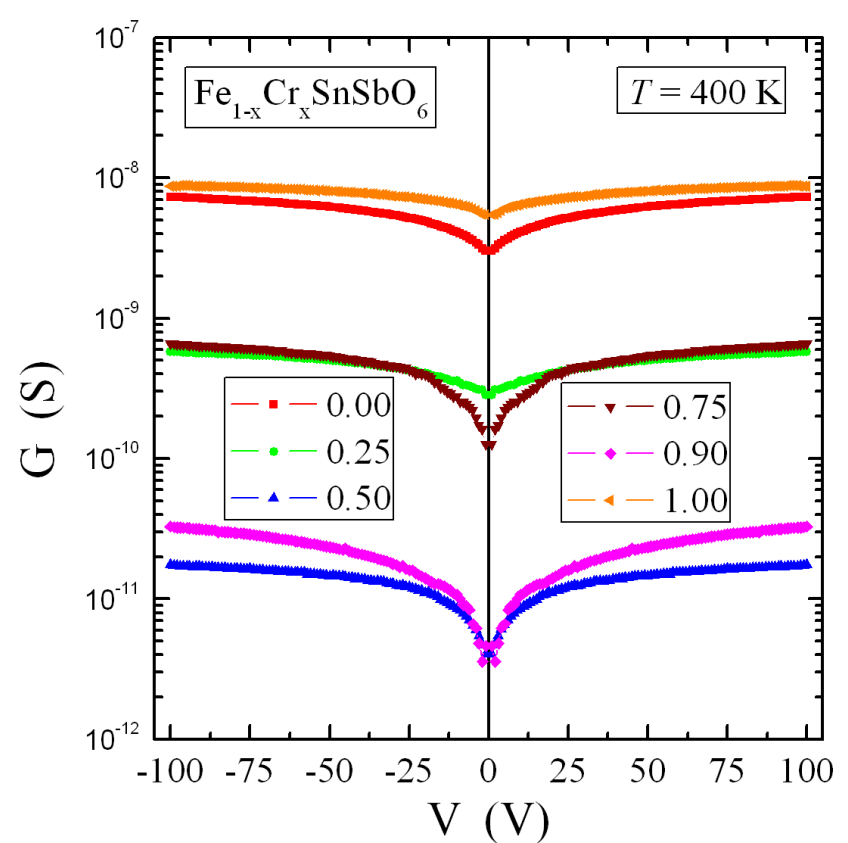

Fig. 5. Conductance $G$ vs. the applied voltage $V$ of $\mathrm{Fe}_{1-x} \mathrm{Cr}_{x} \mathrm{SnSbO}_{6}$ at $400 \mathrm{~K}$.

1. Poole effect according to the relationship: $G \propto$ $\exp (\alpha E)$ [7], where $G$ is the conductance, $E$ is the electric field and $\alpha$ is a constant,

2. Poole-Frenkel effect according to the relationship: $G \propto \exp \left(\beta(E)^{1 / 2}\right)[8]$, where $\beta$ is a constant,

3. phonon assisted tunneling $[9,10]$,

4. direct tunneling for $E>10^{7} \mathrm{~V} / \mathrm{cm}[10,11]$.

Two recent cases concern the low temperatures and strong electric fields.

The results of rough simulations of the Poole-Frenkel model for the chosen solid solution $\mathrm{Fe}_{1-x} \mathrm{Cr}_{x} \mathrm{SnSbO}_{6}$ $(x=0.00,0.25,0.5)$ at $400 \mathrm{~K}$ are presented in Fig. 6 . These simulations showed best fit for the following functions: $G=2.5 \times 10^{-9} \exp \left(0.15 \times(V)^{1 / 2}\right)$ for $x=0.00$, $G=2.5 \times 10^{-10} \exp \left(0.1 \times(V)^{1 / 2}\right)$ for $x=0.25$, and $G=3 \times 10^{-12} \exp \left(0.31 \times(V)^{1 / 2}\right)$ for $x=0.50$. From the graph (Fig. 6) one can see that only in the low voltage up to $25 \mathrm{~V}$ the carrier emission follows according to the Poole-Frenkel model. It is worth noting that the highest emission of electrons is observed for boundary compounds, and much smaller for their solid solutions.

\section{Conclusions}

The results mentioned above suggest that the $n$-type electrical conductivity may be connected with the competition between the mixed valence of $\mathrm{Fe}^{3+}$ and $\mathrm{Fe}^{2+}$ ions (responsible for the $n$-type conductivity) as it was observed in $\mathrm{Fe}_{2} \mathrm{~V}_{4} \mathrm{O}_{13}$ doped with Mo [12]. For the

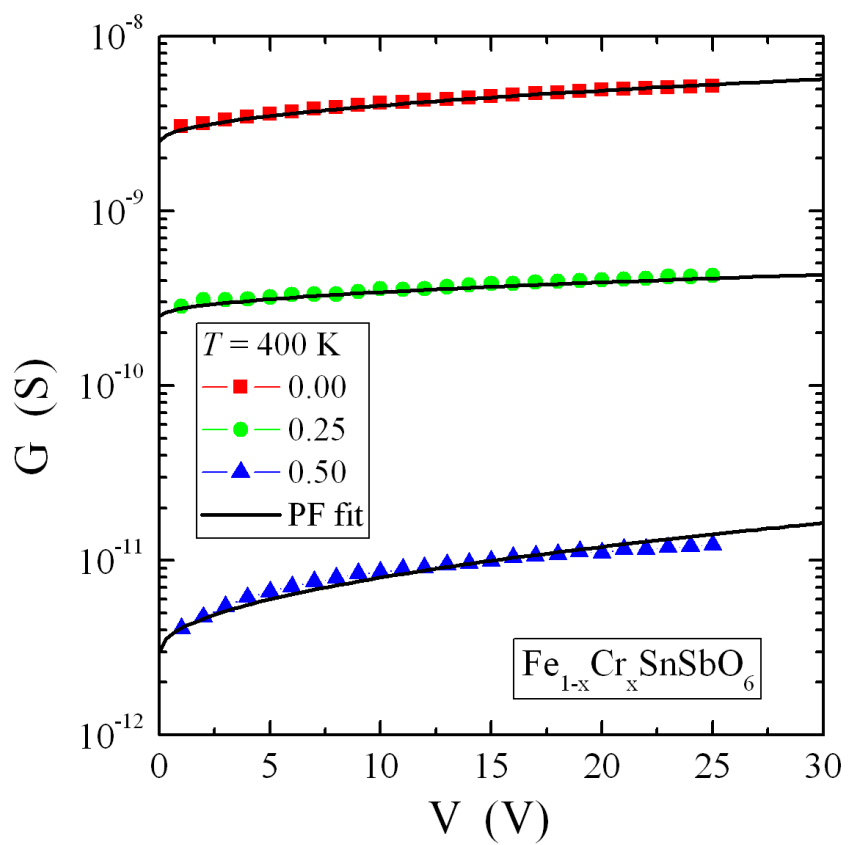

Fig. 6. Conductance $G$ vs. the applied voltage $V$ at $400 \mathrm{~K}$ for $\mathrm{Fe}_{1-x} \mathrm{Cr}_{x} \mathrm{SnSbO}_{6}(x=0.0,0.25,0.50)$. Simulation of Poole-Frenkel (PF) model is marked by solid line.

$\mathrm{CrSnSbO}_{6}$ matrix the $n$-type conductivity may be mainly due to the presence of oxygen vacancies. As in the case of a surplus of oxygen ions, as it is, for example, in $\mathrm{Cr}_{2} \mathrm{~V}_{4-x} \mathrm{Mo}_{x} \mathrm{O}_{13+0.5 x}$ [13] the hole conductivity is observed. Alternatively, the increase of both the intrinsic conductivity and emission of electrons can also come from the charge compensation linked with the recombination of the current carriers, which takes place throughout the localized states in the forbidden band [14] or from the Poole-Frenkel field-assisted emission mechanism [15]. The nature of these states can be linked with the existence of the structure defects and the grain-boundaries with the depletion layers of the adjacent grains.

\section{Acknowledgments}

This work was partly supported by Ministry of Scientific Research and Information Technology (Poland) and funded from science resources: No. 1S-0300-500-1-05-06.

\section{References}

[1] J. Isasi, L. Veiga, C. Pico, J. Mater. Sci. Lett. 15, 1022 (1996).

[2] V.A. Govorov, A.M. Abakumov, M.G. Rozova, A.G. Borzenko, S.Yu. Vassiliev, V.M. Mazin, M.I. Afanasov, P.B. Fabritchnyi, G.A. Tsirlina, E.V. Antipov, E.N. Morozova, A.A. Gippius, V.V. Ivanov, G. Van Tendeloo, Chem. Mater. 17, 3004 (2005).

[3] E. Filipek, G. Dąbrowska, Patent RP No. P400477, 2014. 
[4] P. Kubelka, F. Munk, Z. Tech. Phys. 12, 593 (1931).

[5] G. Dąbrowska, E. Filipek, M. Piz, Ceram. Int. 41, 12560 (2015).

[6] G.B. Beneventi, L. Guarino, M. Ferro, P. Fantini, J. Appl. Phys. 113, 044506 (2013).

[7] H.H. Poole, Philos. Mag. 32, 112 (1916).

[8] J. Frenkel, Phys. Rev. 54, 647 (1938).

[9] V. Karpus, V.I. Perel, Zh. Eksp. Teor. Fiz. 91, 2319 (1986)

[10] S.D. Ganichev, E. Ziemann, W. Prettl, I.N. Yassievich, A.A. Istratov, E.R. Weber, Phys. Rev. B 61, 10361 (2000).

[11] S.D. Ganichev, W. Prettl, I.N. Yassievich, Fiz. Tverd. Tela 39, 1905 (1997)
[12] T. Groń, J. Krok, M. Kurzawa, J. Walczak, J. Magn. Magn. Mater. 54-57, 1301 (1986).

[13] T. Groń, H. Duda, J. Krok-Kowalski, J. Walczak, E. Filipek, A. Wyrostek, K. Bärner, Radiat. Eff. Def. Solids 133, 335 (1995).

[14] T. Groń, H. Duda, J. Warczewski, Phys. Rev. B 41, 12424 (1990).

[15] T. Groń, E. Filipek, M. Piz, H. Duda, T Mydlarz, Mater. Res. Bull. 48, 2712 (2013). 